American J. of Engineering and Applied Sciences 2 (2): 381-387, 2009

ISSN 1941-7020

(C) 2009 Science Publications

\title{
Geometric Optimization of Three-Phalanx Prosthesis Underactuated Fingers using Particles Swarm Algorithm
}

\author{
${ }^{1}$ Somar M. Nacy, ${ }^{2}$ Shaker S. Hassan and ${ }^{2}$ Sadeq Hussein Bakhy \\ ${ }^{1}$ Department of Manufacturing Operations Engineering, \\ Al-Khwarizmi College of Engineering, University of Baghdad, Iraq \\ ${ }^{2}$ Department of Machines and Equipments Engineering, University of Technology, Iraq
}

\begin{abstract}
Problem statement: One are now interested to investigate the optimum design procedure for a finger driving mechanism to have a good configuration of the finger for its utilization in hand prosthesis. A Geometric Optimization of Three-Phalanx Prosthesis Underactuated Fingers (TPPUF) based on a Particle Swarm Optimization (PSO) was presented. Approach: Firstly, a numerical evaluation of the human-like motion was obtained by using an anthropomorphic finger mechanism. Secondly, the dimensional design of a finger driving mechanism had been formulated as a multiobjective optimization problem by using evaluation criteria for fundamental characteristics that were associated with finger motion, grasping equilibrium and force transmission. Results: Testing results indicated that the proposed PSO gives high-quality result and shorter computation time compared with genetic algorithm. Conclusion: Using the PSO Algorithm with the Matlab-software, it is possible to identify all the necessary parameters of the mathematical models.
\end{abstract}

Key words: Particle swarm optimization, genetic algorithm, three-phalanx prosthesis underactuated fingers

\section{INTRODUCTION}

A human hand is a complex structure having 21 Degrees Of Freedom (DOF): Four DOF per finger which has three phalanges and one metacarpus and five DOF for the thumb which has two phalanges and one metacarpus. Figure 1 shows a hand physiology. It can perform grasping, holding and pinching operations while manipulating objects of various sizes, weights and shapes. To mechanically simulate these functions, planar mechanisms with one DOF are generally used in mechanical hands ${ }^{[1-4]}$.

Over the past several years trends in prosthetic hand research have dictated a move away from grippers having only two rigid fingers and no phalanges, focusing more on hands with at least three to five functional fingers, each with two to three phalanges ${ }^{[5]}$. Several types of electric powered hand prosthesis with four functional fingers and a thumb have been created in an attempt to increase user acceptance and satisfaction. The idea to approach the spatial complement of the shape of an object to ensure a distributed grasp is rather common in biologicallyinspired robotics: E.g., snake robots or elephant trunks.
They belong to what has been defined as the FrenetSerret manipulators ${ }^{[6]}$ intended for whole-arm manipulation $^{[7]}$. General grasping processes have also been discussed in ${ }^{[8]}$.

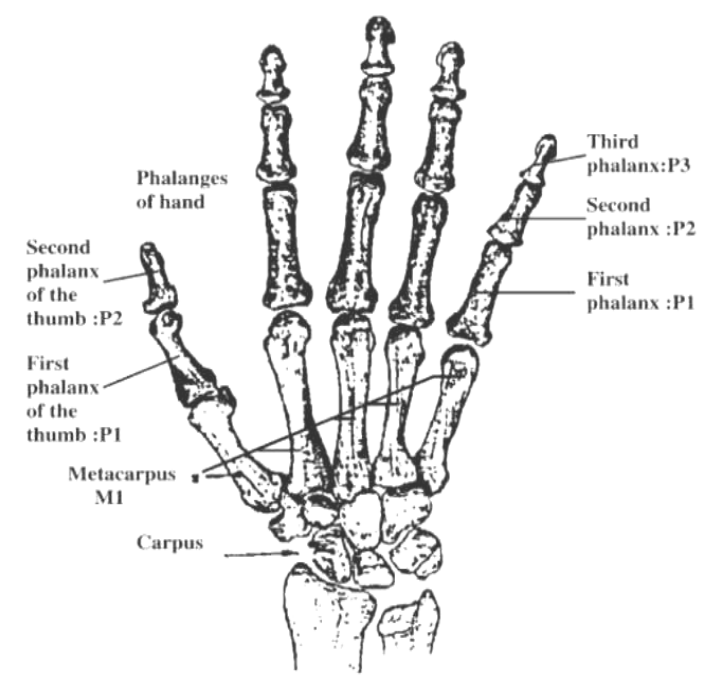

Fig. 1: Physiology of a human hand

Corresponding Author: Somar M. Nacy, Department of Manufacturing Operations Engineering, Al-Khwarizmi College of Engineering, University of Baghdad, Iraq 
In fact, for the users good hand prosthesis should be cosmetically attractive, comfortable enough to wear it all day long and be sufficiently controllable to execute easily with it daily task ${ }^{[9,10]}$. The technology and expertise has crossed over into and benefited the area of prosthetic hand design ${ }^{[11]}$, hands are available for industrial and non-industrial applications.

In order for the previously described parameters to be met optimum sizing of finger driving mechanisms by using fundamental characteristics regarding with the human-like behavior, grasp efficiency and force transmission, identification solution based on the Particle Swarm Optimization (PSO) was proposed in this study. However, significant efforts have been made to find designs that are simple enough to be easily built and controlled in order to obtain practical systems, particularly in human prosthetics.

\section{MATERIALS AND METHODS}

Force properties of underactuated fingers: Underactuation in robotic fingers is different from the concept of underactuation usually presented in robotic systems and both notions should not be confused. An underactuated robot is generally defined as a manipulator with one or more unactuated joints. On the other hand, underactuated fingers generally use elastic elements in their "unactuated" joints. Thus, one should rather think of these joints as uncontrollable or passively driven instead of unactuated. In an underactuated finger, the actuation wrench ta is applied to the input of the finger and is transmitted to the phalanges through suitable mechanical elements, e.g., four-bar linkages. Since underactuated fingers have many degrees of freedom and fewer actuators, passive elements are used to kinematically constrain the finger and ensure the shape-adaptation of the finger to the object grasped. To this end, springs and mechanical limits are often used. An example of underactuated two-phalanx finger using linkages and its closing sequence are shown in Fig. 2. The actuation torque ta is applied to the first link which transmits the effort to all phalanges. Notice the mechanical limit that allows a pre-loading of the spring to prevent any undesirable motion of the second phalanx and also to prevent hyperextension of the finger. Springs are useful for keeping the finger from incoherent motion, but when the grasp sequence is complete, they still oppose the actuation. Thus, springs shall be designed with the smallest stiffness possible, however sufficient to keep the finger from collapsing. With practical prototypes, one has to ensure that grasps are stable in the sense that ejection is prevented. Indeed, an ideal grasping sequence as shown in Fig. 2 does not always occur.
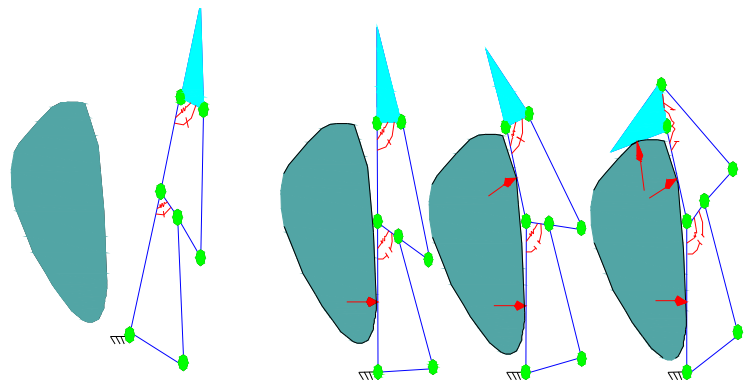

Fig. 2: Ideal grasping sequence of a three-phalanx finger with linkage transmission

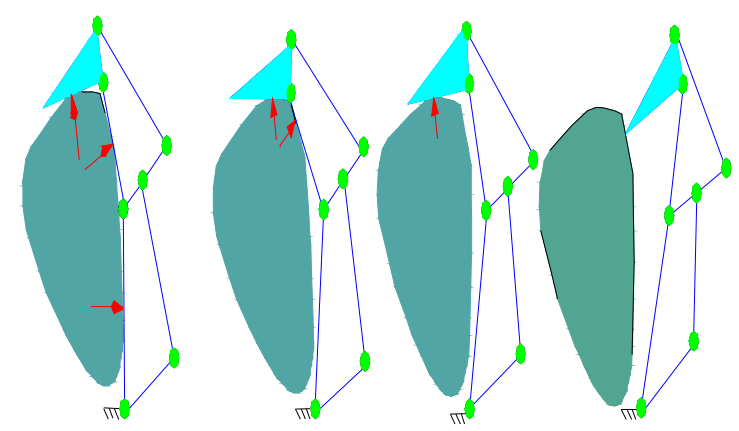

Fig. 3: Example of an ejection sequence for a threephalanx finger with linkage transmission

For in the final configuration some phalanx forces may be negative. If one-phalanx force is negative the corresponding phalanx will loose contact with the object. Then, another step in the grasping process will take place: the remaining phalanges corresponding to positive forces will slide on the object surface. This sliding process will continue until either a stable configuration is achieved, or the last phalanx will curl away and loose contact with the object (Fig. 3).

Static equilibrium: A particular design of underactuated finger will be simplified version of the finger that was used in the Mars and Sarah M1 prototypes $^{[12]}$.

Figure 4 shows the tow models. The actuation torque ta is applied to the link a1 (or pulley $\mathrm{r} 1$ ) which transmits the effort to the phalanges. A rotational springs $\mathrm{t}_{2}, \mathrm{t}_{3}$ in $\mathrm{O}_{2}, \mathrm{O}_{3}$ are used to keep the finger from incoherent motions.

In order to determine the configurations where the finger can apply forces to the object grasped, we shall proceed with a quasi-static modeling of the finger. The latter will provide us with the relationship between the input actuator torque and the forces exerted on the object. 
Am. J. Engg. \& Applied Sci., 2 (2): 381-387, 2009

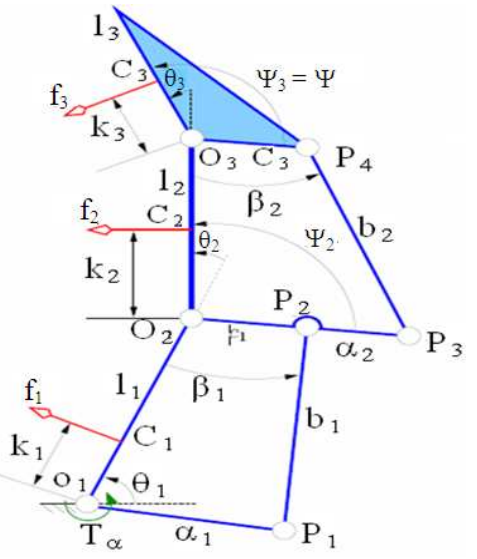

(a)

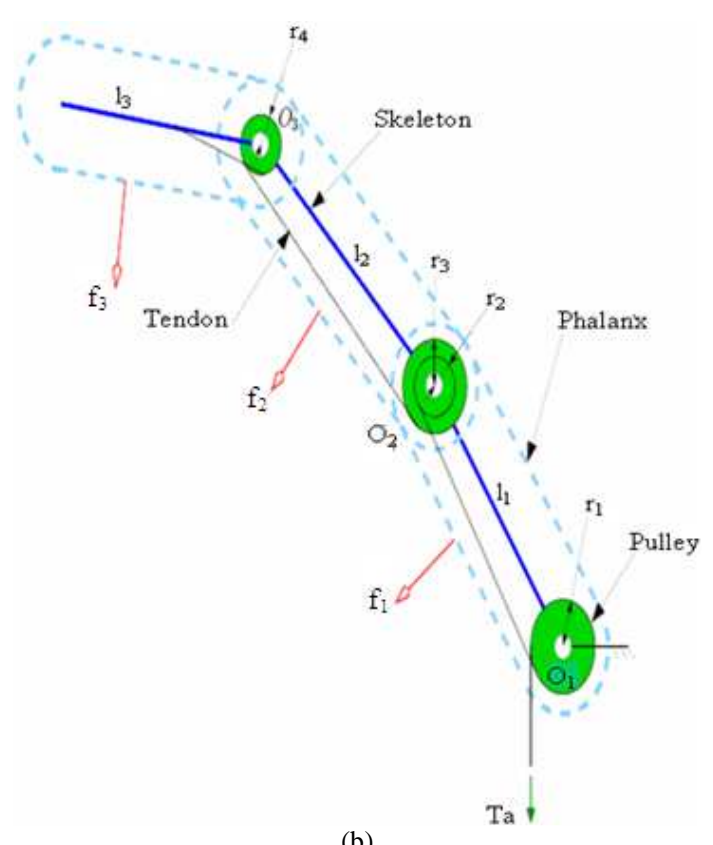

(b)

Fig. 4: Model of underactuated three-phalanx finger using (a): Linkages (b): Tendons

Equating the input and the output virtual powers, one obtains:

$f=J^{-T} T^{-T} t$

where, $f=\left[f_{1}, f_{2}, f_{3}\right]^{T}$ the vector of normal contact forces and $t$ is the input torque vector exerted by the actuator and the springs, i.e., $t=\left[\mathrm{T}_{1}, \mathrm{~T}_{2}, \mathrm{~T}_{3}\right]^{\mathrm{T}}$. Matrix $\mathrm{J}$ is a lower triangular matrix characteristic of the contact locations and friction, if modeled. That can be expressed analytically. Neglecting friction, one has:

$$
J=\left[\begin{array}{ccc}
k_{1} & 0 & 0 \\
k_{2}+l_{1} C_{\theta_{2}} & k_{2} & 0 \\
k_{3}+l_{1} C_{\theta_{2}+\theta_{3}}+l_{2} C_{\theta_{3}} & k_{3}+l_{2} C_{\theta_{3}} & k_{3}
\end{array}\right]
$$

where, $\mathrm{C}_{\theta}=\operatorname{Cos} \theta$ symbols are indicated in Fig. 5. It is observed that this matrix can also used with fullyactuated fingers. Matrix $\mathrm{T}$ is characteristic of underactuation. It becomes the identity matrix for fullyactuated fingers) and, more precisely, of the transmission mechanism used. For a finger using linkages as shown in Fig. 4 or have:

$$
\mathrm{T}=\left[\begin{array}{ccc}
1 & -\frac{\mathrm{h}_{2}}{\mathrm{~h}_{2}+\mathrm{l}_{1}} & \frac{\mathrm{h}_{2} \mathrm{~h}_{3}}{\left(\mathrm{~h}_{2}+\mathrm{l}_{1}\right)\left(\mathrm{h}_{3}+\mathrm{l}_{2}\right)} \\
0 & 1 & 0 \\
0 & 0 & 1
\end{array}\right]
$$

$\mathrm{h}_{\mathrm{i}}=\mathrm{c}_{\mathrm{i}-1}\left(\cos \left(\varphi_{\mathrm{i}}-\psi_{\mathrm{i}}\right)-\sin \left(\varphi_{\mathrm{i}}-\psi_{\mathrm{i}}\right) \cot \beta_{\mathrm{i}-1}\right)$

is the signed distance between point $\mathrm{O}_{\mathrm{i}}$ and the geometric intersection of lines $\left(\mathrm{O}_{\mathrm{i}-1} \mathrm{O}_{\mathrm{i}}\right)$ and $\left(\mathrm{P}_{2 \mathrm{i}-2} \mathrm{P}_{2 \mathrm{i}-3}\right)$. This value can he negative if the intersection point is on the same side as $\mathrm{O}_{\mathrm{i}-1}$ with respect to $\mathrm{O}_{\mathrm{i}}$. Angle $\Psi_{\mathrm{i}}$ is the angle between $\mathrm{O}_{\mathrm{i}} \mathrm{P}_{2 \mathrm{i}-2}$ and $\mathrm{O}_{\mathrm{i}+1} \mathrm{O}_{\mathrm{i}}$ for $\mathrm{i}>1$, i.e.:

$$
\begin{aligned}
\psi_{i}= & a \tan \left[\frac{-c_{i} \sin \left(\theta_{i+1}-\psi_{i+1}\right)}{1_{i}+c_{i} \cos \left(\theta_{i+1}-\psi_{i+1}\right)}\right]+a \cos \\
& {\left[\frac{l_{i}^{2}+a_{i}^{2}+c_{i}^{2}-b_{i}^{2}+2 c_{i} l_{i} \sin \left(\theta_{i+1}-\psi_{i+1}\right)}{2 a_{i} \sqrt{l_{i}^{2}+c_{i}^{2}+2 c_{i} l_{i} \sin \left(\theta_{i+1}-\psi_{i+1}\right)}}\right] }
\end{aligned}
$$

Hence, For a linkage-driven finger, the expressions of the contact forces are:

$$
\begin{aligned}
& \mathrm{f}_{1}=\frac{\mathrm{l}_{1} \mathrm{UT}_{\mathrm{a}}}{\mathrm{k}_{1} \mathrm{k}_{2} \mathrm{k}_{3}\left(\mathrm{~h}_{2}+\mathrm{l}_{1}\right)\left(\mathrm{h}_{3}+\mathrm{l}_{2}\right)} \\
& \mathrm{f}_{2}=\frac{\mathrm{h}_{2} \mathrm{l}_{2}\left(\mathrm{k}_{3}-\mathrm{h}_{3} \cos \theta_{3}\right) \mathrm{T}_{\mathrm{a}}}{\mathrm{k}_{2} \mathrm{k}_{3}\left(\mathrm{~h}_{2}+\mathrm{l}_{1}\right)\left(\mathrm{h}_{3}+\mathrm{l}_{2}\right)} \\
& \mathrm{f}_{3}=\frac{\mathrm{h}_{2} \mathrm{l}_{2} \mathrm{~T}_{\mathrm{a}}}{\mathrm{k}_{3}\left(\mathrm{~h}_{2}+\mathrm{l}_{1}\right)\left(\mathrm{h}_{3}+\mathrm{l}_{2}\right)}
\end{aligned}
$$

Where:

$$
\begin{aligned}
\mathrm{U}= & \mathrm{k}_{2} \mathrm{k}_{3} \mathrm{~h}_{3}+\mathrm{k}_{2} \mathrm{k}_{3} \mathrm{l}_{2}-\mathrm{h}_{2} \mathrm{k}_{3} \mathrm{l}_{2} \cos \theta_{2}+ \\
& \mathrm{h}_{2} \mathrm{~h}_{3} \mathrm{l}_{2} \cos \theta_{2} \cos \theta_{3}-\mathrm{h}_{2} \mathrm{~h}_{3} \mathrm{k}_{2} \cos \left(\theta_{2}+\theta_{3}\right)
\end{aligned}
$$


and for tendon-driven fingers, the expressions are simpler, i.e., one has:

$$
\mathrm{T}=\left[\begin{array}{ccc}
1 & -\frac{\mathrm{r}_{2}}{\mathrm{r}_{1}} & -\frac{\mathrm{r}_{2} \mathrm{r}_{4}}{\left(\mathrm{r}_{1} \mathrm{r}_{3}\right)} \\
0 & 1 & 0 \\
0 & 0 & 1
\end{array}\right]
$$

where, $r 2 \mathrm{i}-1$ and $\mathrm{r} 2 \mathrm{i}$ for $\mathrm{i}>0$ are respectively the radius of the pulley located at the base and at the end of the ith phalanx (cf. Fig. 4b).

Hence, for tendon-driven fingers, the expressions of the contact forces are:

$$
\begin{aligned}
\mathrm{f}_{1}= & \frac{\mathrm{U}^{\prime} \mathrm{T}_{\mathrm{a}}}{\mathrm{k}_{1} \mathrm{k}_{2} \mathrm{k}_{3} \mathrm{r}_{1} \mathrm{r}_{3}} \\
\mathrm{f}_{2}= & \frac{-\mathrm{r}_{2}\left(-\mathrm{k}_{3} \mathrm{r}_{3}+\mathrm{r}_{4} \mathrm{l}_{2} \cos \theta_{3}+\mathrm{r}_{4} \mathrm{k}_{3}\right) \mathrm{T}_{\mathrm{a}}}{\mathrm{k}_{2} \mathrm{k}_{3} \mathrm{r}_{1} \mathrm{r}_{3}} \\
\mathrm{f}_{3}= & \frac{\mathrm{r}_{2} \mathrm{r}_{4} \mathrm{~T}_{\mathrm{a}}}{\mathrm{r}_{1} \mathrm{r}_{3} \mathrm{k}_{3}} \\
\mathrm{U}^{\prime}= & 1_{1} \mathrm{r}_{2} \cos \theta_{2}\left(l_{2} \mathrm{r}_{4} \cos \theta_{3}+\left(\mathrm{r}_{4}-\mathrm{r}_{3}\right) \mathrm{k}_{3}\right)+ \\
& \mathrm{k}_{2} \mathrm{k}_{3} \mathrm{r}\left(\mathrm{r}_{1}-\mathrm{r}_{3}\right)-\mathrm{r}_{2} \mathrm{r}_{4} \mathrm{l}_{1} \cos \left(\theta_{2}+\theta_{3}\right)
\end{aligned}
$$

Optimization of the design: Because of the complexity of the system, it is very difficult, in the static model (Eq. 1-10), to isolate each parameter. To solve the problem, a Particle Swarm Optimization (PSO) algorithm was used. The PSO algorithm used was developed by Source Code Library for the software Matlab.

PSO algorithm is similar to that of the evolutionary computation techniques in which a population of potential solutions to the optimal problem under consideration is used to probe the search space. Each potential solution is also assigned a randomized velocity and the potential solutions, called particles, correspond to individuals. Each particle in PSO flies in the D-dimensional problem space with a velocity dynamically adjusted according to the flying experiences of its individuals and their colleagues. The location of the ith particle is represented as D $X_{i}=\left[x_{i 1}, x_{i 2}, \ldots, x_{i D}\right]$, where $X_{i d} \in\left[I_{d}, u_{d}\right], d \in[1, D], \quad I_{d}, u$ are the lower and upper bounds for the dth dimension, respectively. The best previous position (which gives the best fitness value) of the ith particle is recorded and represented as $P_{i}=\left[p_{i 1}, p_{i 2}, \ldots, p_{i D}\right]$, which is also called $\mathrm{P}_{\text {best }}$. The index of the best particle among all the particles in the population is represented by the symbol $\mathrm{g}$. The location $\mathrm{P}_{\mathrm{g}}$ is also denoted by $\mathrm{g}_{\text {best }}$. The velocity of the ith particle is represented by $\mathrm{V}_{\mathrm{i}}=\left[\mathrm{v}_{\mathrm{i} 1}, \mathrm{v}_{\mathrm{i} 2}, \ldots, \mathrm{v}_{\mathrm{iD}}\right]$ and is clamped to a maximum velocity $\mathrm{V}_{\max }=\left[\mathrm{v}_{\max 1}, \mathrm{v}_{\max 2}, \ldots, \mathrm{v}_{\max \mathrm{D}}\right]$, which is specified by the user. The particle swarm optimization concept consists of, at each time step, regulating the velocity and location of each particle toward its $\mathrm{P}_{\text {best }}$ and $\mathrm{g}_{\text {best }}$ locations according to the Eq. 2-3, respectively:

$$
\begin{aligned}
& v_{i d}^{n+1}=w v_{i d}^{n}+c_{1} r_{1}^{n}\left(p_{i d}^{n}-x_{i d}^{n}\right)+c_{2} r_{2}^{n}\left(p_{g d}^{n}-x_{i d}^{n}\right) \\
& x_{i d}^{n+1}=x_{i d}^{n}+v_{i d}^{n+1}
\end{aligned}
$$

where, $\mathrm{w}$ is the inertia weigh; $\mathrm{c}_{1}, \mathrm{c}_{2}$ are two positive constants, called cognitive and social parameter respectively; $\mathrm{d}=1,3, \ldots, \mathrm{D} ; \mathrm{i}=1,3, \ldots, \mathrm{m}$ and $\mathrm{m}$ is the size of the swarm; $r_{1}, r_{2}$ are two random numbers, uniformly distributed in $[0,1]$; and $\mathrm{n}=1,3, \ldots, \mathrm{N}$ denotes the iteration number, $\mathrm{N}$ is the maximum allowable iteration number.

Criteria of optimization: Because the main task of this finger is to grasp objects (so to apply forces to them), it's normal to do the optimization in function of forces criteria for the static model, presented previously. Those criteria were defined to found the parameters and then those criteria are derived from the static model (Eq. 1-10).

A power grasp uses the both phalanxes in comparison with a tip grasp which uses only the distal phalanx. One would like that a power grasp could be possible for all position-orientation of the finger. Mathematically, this means:

$\mathrm{f}_{1}, \mathrm{f}_{2}, \mathrm{f}_{3} \geq 0, \quad \forall \theta$

Because of the contact forces, if those forces are negative, the associated phalanx will move in clockwise directions which get away from the object.

The pinching force is the sum of $f_{1}, f_{2}$ and $f_{3}$ that will be applied on an object. Because this pinching force is generated by the user, the force should be preferably constant, no matter of the positionorientation of the finger. Then to be assuring the stability of the grasp, one needs a certain pinching force. This force should be as high as possible, so this criteria could be mathematically represent as:

$$
\left(\frac{\mathrm{f}_{1}+\mathrm{f}_{2}+\mathrm{f}_{3}}{\mathrm{fa}}\right)_{\max .}=\text { cste, } \quad \forall \theta
$$


Am. J. Engg. \& Applied Sci., 2 (2): 381-387, 2009

With $\mathrm{f}_{\mathrm{a}}=\frac{\mathrm{T}_{\mathrm{a}}}{\mathrm{r}_{1}}$

Parameters to optimize: The fingers of the hand prosthesis optimization are a function of the size of the hand. Here, a glove ${ }^{[12]}$ of the company Otto Buck was used to define the parameters boundaries.

\section{RESULTS}

The parameters that had been defined by the optimization are shown in the Fig. 4 and the Table 1 shows the numerical values of the boundaries used for those parameters. (Both have the exact same condition for positiveness! a tendon-actuated finger with pulley radii equivalent to link lengths, i.e., $r_{2 \mathrm{i}-1}=\mathrm{a}_{\mathrm{i}}$ and $\mathrm{r}_{2 \mathrm{i}}=\mathrm{c}_{\mathrm{i}}$ ).

\section{DISCUESSION}

As said before, the goal of this optimization is to find a good solution. Although the PSO method seems to be sensitive to the tuning of some weights or parameters, according to the experiences of many experiments, the following PSO and GA parameters can be used.

\section{PSO method:}

Population size $=100$

Generations $=40$ inertia weight factor $\mathrm{w}$

where, $\mathrm{w}_{\max }=0.7$

$\mathrm{w}_{1} \quad=0.4$

The limit of change in velocity of each member in an individual was:

$\begin{aligned} \mathrm{V}_{\mathrm{P}_{\mathrm{d}}}^{\max } & =0.5 \mathrm{P}_{\mathrm{d}}^{\max } \\ \mathrm{V}_{\mathrm{P}_{\mathrm{d}}}^{\min } & =0.5 \mathrm{P}_{\mathrm{d}}^{\min }\end{aligned}$

Acceleration constant $\mathrm{c}_{1}=2$ and $\mathrm{c}_{2}=2$.

Table 1: Boundaries of parameters to optimized.

\begin{tabular}{llll}
\hline Parameters & Tendon & $\begin{array}{l}\text { Min } \\
\text { values } \\
(\mathrm{mm})\end{array}$ & $\begin{array}{l}\text { Max } \\
\text { values } \\
(\mathrm{mm})\end{array}$ \\
\hline-0 Linkage & $\mathrm{l}_{1}$ & 40 & 60 \\
\hline $\mathrm{l}_{1}$ & $\mathrm{l}_{2}$ & 21 & 35 \\
$\mathrm{l}_{2}$ & 13 & 18 & 26 \\
13 & $\mathrm{r}_{1}$ & 10 & 23 \\
$\mathrm{a}_{1}$ & $\mathrm{r}_{3}$ & 3 & 20 \\
$\mathrm{a}_{2}$ & - & 32 & 70 \\
$\mathrm{~b}_{1}$ & - & 14 & 35 \\
$\mathrm{~b}_{2}$ & $\mathrm{r}_{2}$ & 3 & 20 \\
$\mathrm{c}_{1}$ & $\mathrm{r}_{4}$ & 3 & 15 \\
$\mathrm{c}_{2}$ & $\mathrm{k}_{1}$ & $0.1 \mathrm{l}_{1}$ & $0.91_{1}$ \\
$\mathrm{k}_{1}$ & $\mathrm{k}_{2}$ & $0.1 \mathrm{l}_{2}$ & $0.9 \mathrm{l}_{2}$ \\
$\mathrm{k}_{2}$ & $\mathrm{k}_{3}$ & $0.1 \mathrm{l}_{3}$ & $0.9 \mathrm{l}_{3}$ \\
$\mathrm{k}_{3}$ & & &
\end{tabular}

GA method:

Population size $\quad=100$

Generations $\quad=40$

Crossover rate $\mathrm{P}_{\mathrm{C}} \quad=0.6$

Mute rate $\mathrm{P}_{\mathrm{m}} \quad=0.05$

Crossover parameter $\mathrm{a}=0.5$

The optimizations used a variation of $\theta_{1}$ and $\theta_{2}$ from $200^{\circ}$ to $-200^{\circ}$. This seems to be a reasonable workspace for this application of the finger. Table 2, the parameters found by three optimizations method and the absolute error, Mean Absolute Error (MAE) and Maximum error (Max) is also compared for Largescale Unconstrained Nonlinear (indicated as LSUN) and Genetic Algorithm (indicated as GA) and Particle Swarm Optimization (indicated as PSO) estimator in Table 1 and 2.

From the analysis of the results in Table 2, it is observed that the accuracy of the (PSO) algorithm is slightly superior when compared with the (GA) algorithm on account of Mean Average Error (MAE) this comparison is $2.75<2.79$ for parameter's.

The computational time is the least, for the (PSO), the GA computational time is less as compared with the SLUN method as indicated in Table 2.

The constant pinching force was evaluated using the standard deviation (sd). Figure 5-7 shows the statistical data of the forces. One can see that solution by PSO has the smallest s.d. More over this solution has interesting parameters.

Finally, for all those reasons, PSO solution was preferred and declared "the optimal solution.
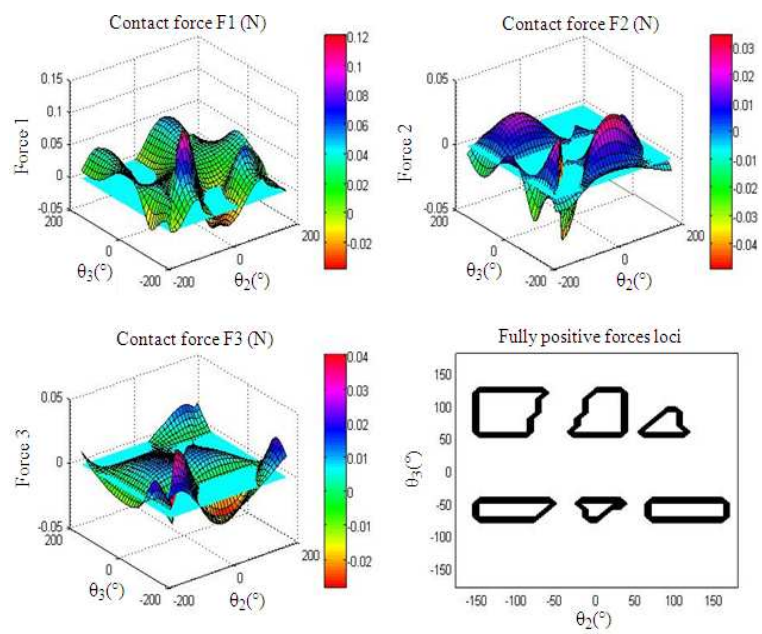

Fig. 7: The force distribution (PSO optimization method) 
Am. J. Engg. \& Applied Sci., 2 (2): 381-387, 2009

Table 2: Optimal parameters of by using three methods (for a linkage-driven finger)

\begin{tabular}{lcrrll}
\hline Para. $(\mathrm{mm})$ & LSUN & \multicolumn{1}{l}{ GA } & PSO & Error GA & Error GA \\
\hline $\mathrm{l}_{1}$ & 47.0 & 40.00 & 46.00 & 7.00 & 6.00 \\
$\mathrm{l}_{2}$ & 27.0 & 26.00 & 28.00 & 1.00 & 1.00 \\
$\mathrm{l}_{3}$ & 20.0 & 19.00 & 15.00 & 1.00 & 4.00 \\
$\mathrm{a}_{1}$ & 20.5 & 17.00 & 20.00 & 3.50 & 0.50 \\
$\mathrm{a}_{2}$ & 17.0 & 14.00 & 18.00 & 3.00 & 1.00 \\
$\mathrm{~b}_{1}$ & 46.0 & 43.00 & 48.00 & 3.00 & 2.00 \\
$\mathrm{~b}_{2}$ & 30.0 & 27.00 & 32.00 & 3.00 & 2.00 \\
$\mathrm{c}_{1}$ & 12.0 & 9.00 & 19.00 & 3.00 & 7.00 \\
$\mathrm{c}_{2}$ & 9.0 & 6.00 & 16.00 & 3.00 & 7.00 \\
$\mathrm{k}_{1}$ & 23.5 & 20.00 & 23.50 & 3.50 & 0.00 \\
$\mathrm{k}_{2}$ & 13.5 & 13.00 & 14.00 & 0.50 & 0.50 \\
$\mathrm{k}_{3}$ & 10.0 & 8.50 & 7.50 & 1.50 & 2.50 \\
MAE & & & & 2.79 & 2.75 \\
Max & & & & 7.00 & 7.00 \\
Time (sec) & 0.43 & 0.52 & 0.83 & & \\
\hline
\end{tabular}
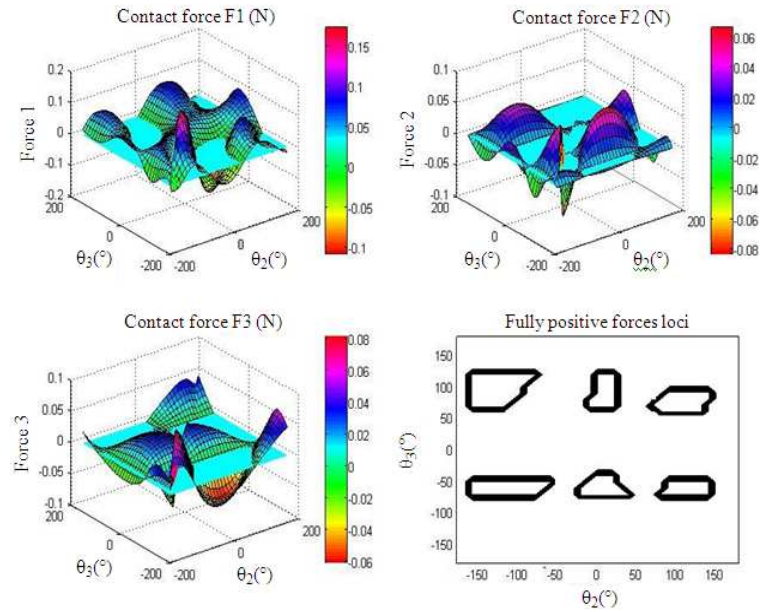

Fig. 5: The force distribution (SLUN optimization method
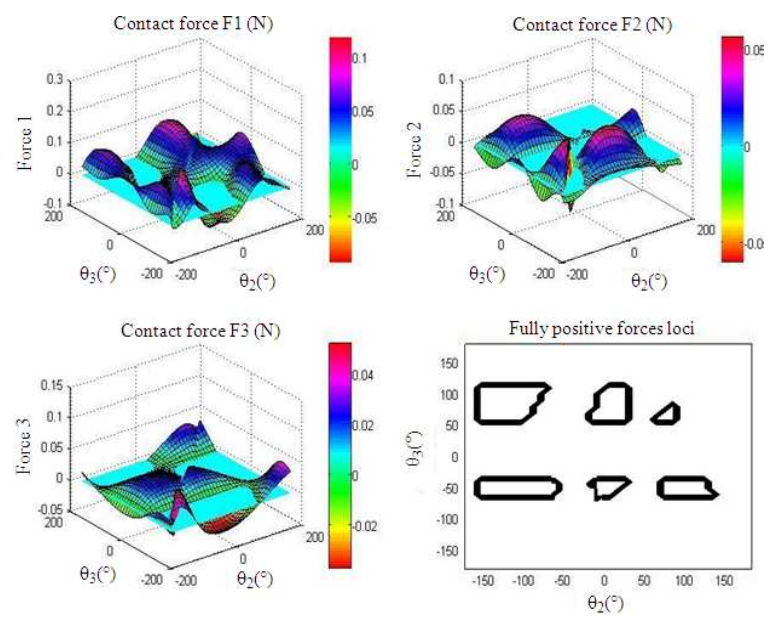

Fig. 6: The force distribution (GA optimization method)

\section{CONCLUSION}

The new underactuated finger seems to be very interesting for a hand prosthesis use. The simplicity of the design and its self adaptation to different shapes of objects are some qualities that give it a good chance to be successful in prosthetics. This study has presented and analyzed the force capabilities of underactuated fingers of a three-phalanx finger considering geometry of the contact and optimal phalanx force distribution, two different methods, a genetic algorithm and a Particle swarm optimization method. An optimization was done to find a good configuration of the parameters of the finger. The design problem has been formulated as a multi-objective optimization problem. The numerical procedure is characterized by fairly simple formulations for the optimality criteria and no great computational efforts in order to achieve practical optimal design solutions. To ensure a stable grasp, ejection must be prevented. The future work is to study the controllability of an underactuated hand based on these results.

\section{ACKNOWLEDGEMENT}

The researchers thank the department of Machines and Equipments Engineering, of WHO that funded the project with resources received for research from university of Technology.

\section{REFERENCES}

1. Ngale Haulin, E., R. Vinet and Z. Klim, 1998. Influence of material and the reliability on the optimal design of machine elements. Proceeding of CSME Forum, (CSMEF'98), pp: 86.

2. Guo, G., Q.X. Qian and W.A. Gruver, 1992. A single-DOF multi-function prosthetic hand mechanism with automatically variable speed transmission. Proceeding of the 22nd Biennial Mechanisms Conference on Robotics, Spatial Mechanisms and Mechanical Systems, ASME Design Engineering Division, DE., pp: 149-154.

3. Guo, G. and J. Zhang, 1993. Optimal design of a six-bar linkage with one degree of freedom for an anthropomorphic three jointed finger mechanism. Inst. Mech. Eng., 207: 185-190. http://www.ncbi.nlm.nih.gov/pubmed/8117370

4. Vinet, R., Y. Lozach, N. Beaudry and G. Drouin, 1995. Design methodology for a multifunctional hand prosthesis. J. Rehabil. Res. Dev., 32: 316-324. http://www.ncbi.nlm.nih.gov/pubmed/8770796 
5. Rakic Midrag, 1989. Multifingered Robot Hand with self adaptability. Robot. Comput. Integrat. Manufactur., 5: 269-276.

6. Salisbury, K., 1987. Whole arm manipulation. Proceedings of the 4th International Symposium on Robotics Research, Aug. 9-14, Santa Cruz, California, USA., pp: 183-189.

7. Panagiotopoulos, P.D. and A.M. Al-Fahed, 1994. Robot hand grasping and related problems: Optimal control and identification. Int. J. Robot. Res., 13: 127-136.

DOI: 10.1177/027836499401300203

8. Plettenburg, D.H. and J.C. Cool, 1992. Upper extremity prostheses; the WILMER approach. Proceedings of the 7th ISPO World Congress, June 28-July 3, Chicage, USA., pp: 331.

9. Plettenburg, D.H. and J.L. Herder, 2003. Voluntary closing: A promising opening in hand prosthetics. Technol. $\quad$ Disabil., 15: 85-94. http://iospress.metapress.com/content/yrr52lpmkpx nrhq5/
10. Dechev, N., W.L. Cleghorn and S. Naumann, 2001. Multi-segmented finger design of an experimental prosthetic hand. Proceeding of the Conference on Applied Mechanisms and Robotics, Dec. 15-15, Cincinnati, $\quad$ pp: 1-8. http://www.mie.utoronto.ca/staff/projects/cleghorn/grads tudents/AMR1999-DechevCleghornNaumann.pdf

11. Gosselin, C. and T. Laliberte, 1996. Underactuated mechanical finger with return actuation. US Patent No. 5762390. http://www.wikipatents.com/5762390.html

12. Birglen, L. and M.C. Gosselin, 2006. Grasp-state plane analysis of two-phalanx underactuated fingers. Mechan. Mach. Theor., 41: 807-822. DOI: 10.1016/j.mechmachtheory.2005.10.004 